\title{
LINGÜÍSTICA TEXTUAL EM EXERCÍCIOS
}

Carlos Alexandre Victório Gonçalves*

\section{Resumo:}

Neste artigo, apresento uma proposta de aplicação dos postulados da Lingüística Textual ao ensino de lingua portuguesa em escolas de $1^{\circ}$ e $2^{\circ}$ graus, buscando converter em exercicios práticos questões teóricas referentes à coesão, à superestrutura e à coerência, entre outras, alicerces do edificio teórico da Lingüistica Textual

\section{O.Introdução}

A tradição pedagógica do ensino de lingua portuguesa nas escolas de $1^{\circ} \mathrm{e}$ $2^{\circ}$ graus tende a investir, muitas vezes, na aprendizagem de taxonomias gramaticais, esperando que, com isso, auxilie o aluno a agir com independência perante o material impresso a que tem acesso. De fato, na maior parte das gramáticas escolares, "ensina-se" os alunos a classificar orações e a depreender os significados dos morfemas da lingua, entre outras tarefas, na esperança de que eles redijam textos. A tradição gramatical, ao assim proceder, considera o texto como somatório de frases e como subproduto da gramaticalização e não como um todo orgânico, com regras e leis próprias (Ilari, 1986).

Ao que parece, a grande maioria dos livros didáticos destinados ao ensino de português como $\mathrm{L} l$ trata o texto apenas como pretexto para um ensino de tópicos de gramática referentes ao vocábulo e, com menor frequiência, à frase. Os exercícios de interpretação, muito escassos, não apresentam, na maior parte das vezes, nenhum desafio intelectual ao aluno, uma vez que tendem a ser utilizados apenas para reforçar a leitura linear e superficial do texto. $\mathrm{Na}$ verdade, na grande maioria dos manuais de ensino de língua portuguesa, texto é pretexto para ensino metalingüístico.

Com base nesses dados, pretendo, neste artigo, apresentar e discutir a proposta de Silva (1992), aplicando os postulados teóricos da Lingüistica Textual ao ensino de leitura em lingua materna, mais especificamente em língua portuguesa.

- Doutorando em Lingüistica pela UFRJ e professor de Linguja Portuguesa do Departamento de Letras Vemáculas da Faculdade de Letras da UFRJ. 
Pretendo, assim, apresentar e ampliar os achados do trabalho acinia citado, convertendo em exercícios práticos questões teóricas referentes à Superestrutura (Van Dijk, 1981), à Coesão (Koch, 1989) e à Coerência (Koch \& Travaglia, 1989 e 1990), entre outras, alicerces do edifício teórico da Lingüistica Textual. Para tanto, estabeleço o estudo do texto em três tempos, denominados, neste artigo, de: (a) Pré-Texto, recuperando Silva (op. cit.); (b) Gramática do Texto; e (c) TransTexto. Com isso, busco ampliar a proposta de Silva (op. cit.), principalmente em relação aos fatores referentes à coerência do texto, tais como a situacionalidade $\mathrm{e}$ a intencionalidade, $\mathrm{e}$ ao estudo da coesão seqüencial (Koch, 1989).

Os objetivos centrais da proposta que ora apresento são basicamente três: (a) incluir o ensino de leitura e produção de textos na prática diária do ensino de lingua portuguesa nos níveis básico e secundário; (b) analisar o texto de uma forma mais globalizante, tanto em seus aspectos lingüísticos como interacionais; e (c) estudar os usos lingüísticos reais, visando a levar o aluno a perceber que a língua é um fenômeno variável nas diversas situações de uso, diferentemente da prática tradicional, que considera a língua como existente somente na modalidade culta.

\section{Pré-Texto (e pretexto): em busca das "âncoras"}

Nesta etapa do trabalho, denominada de Pré-Texto, os alunos, ainda sem a leitura prévia do texto a ser estudado, fazem todas as inferências possiveis, a partir do título, do que possa vir a ser tratado no texto. Na maioria das vezes, o título de um texto já lhe detennina o topic, pois o leitor o atualiza como indicador temático. 0 título de um texto, ilustram Koch \& Travaglia (1990: 68), permite prever sobre o que o texto fala. Assim, conforme aponta Marcuschi (1983: 20), é o título de um texto que tem o poder de avançar comunicativamente elementos cognitivos em termos de expectativas. Sua escolha pode decidir a orientação da leitura, pois ele é um processo atual num texto atual.

Através de uma seçâo de exercícios, este momento do trabalho tem por objetivo ativar a capacidade de predição e adivinhação dos alunos acerca de possíveis conteúdos textuais. Assim, admite-se, com Vigner (1989: 36), que ler não é mais uma entrada em espaços desconhecidos; $\dot{e}$, mais prosaicamente, a procura de uma confirmação, o acionamento quase automático de protocolos de leitura já constituidos. Desta forma, parto da idéia de que o ato de explorar, nesta etapa do trabalho, aspectos específicos do texto, tais como título, tipo de texto, assunto, entre outros, está diretamente relacionado à ativação da memória textual, pois, como mostra Vigner (op. cit.: 36), os protocolos de leitura se ativam em presença de textos ja repertoriados e identificáveis pelo leitor desde a recepçâo dos primeiros sinais de abertura: titulo, capa, formato, tipografia.

Nesta primeira etapa do trabalho, parte-se, assim, dos chanıdos 'fatores de contextualização', que, embora não sejan considerados como pertencentes ao texto propriamente dito, contribuem, mostra Marcuschi (1983: 16), para equacionar alternativas de compreensão. São os 'sinais éticos' do texto, na medida em que ajudam, ainda segundo Marcuschi (op. cit.: 17), a avançar expectativas em relação ao texto, situando-o num universo contextual de interaçâo. Por essa razão, este momento do trabalho "sonda"/"colhe" o conhecimento prévio do leitor sobre o assunto a ser trabalhado no texto. Como assinala Silva (1989: 04), este é um momen to de bastante importância, nâo só por fornecer dados que ajudarão o aluno a compreender o texto, mas também por trazer ao professor muitas informações a respeito da visão de mundo de seu aluno.

O Pré-Texto permite, portanto, que o professor verifique os conhecimentos de mundo que seus alunos efetivamente possuem a respeito do assunto a ser trabalhado no texto enfocado em aula. Por isso mesmo, talvez sirva para ativar modelos cognitivos globais, como Frames, Scripts, Planos e Esquemas Textuais, pois, como se sabe, só é possível depreender o sentido global de uma texto quando ele fala de coisas que conlecemos. Assim, este momento do trabalho tem como objetivo principal fornecer dicas aos alunos a fim de incentivar o desenvolvimento de sua capacidade de predição.

Para ilustrar melhor as etapas da proposta apresentada, tomarei por base a análise do texto Escuro, de Carlos José Tavares Gomes. Observe-se, a seguir, um Pré-Texto preparado para o texto que servirá como exemplo, neste artigo.

O texto que você irá ler agora se intitula Escuro. Antes de começar sua leitura, façamos algumas reflexões:

1. O que o título do texto Escuro lhe sugere quanto:

(a) ao local onde a estória se passa;

(b) aos personagens;

(c) ao clima da estória?

2. Reflita sobre a afirmação abaixo e faça um comentário sobre ela:

"As idéias relacionadas com a palavra escuro são positivas em nossa sociedade".

3. Faça um levantamento de palavras que se associam, de alguma forma, com a palavra escuro.

4. Pensando nas respostas anteriores, tente adivinhar que tipo de texto o autor escreveu:

(a) um texto em que ele apenas descreve fatos (descritivo)

(b) um texto em que ele relata uma estória (narrativo).

\section{Buscando padrões: a Gramática do Texto}

Depois de se analisar o Pré-Texto, entrega-se o texto aos alunos e dá-se inicio à segunda etapa do trabalho a Gramática do Texto. Esta parte do trabalho 
compreende, de uma fornna geral: (a) a comparação das predições e inferências feitas no Pré-Texto com o que realmente acontece no texto; (b) o estudo da superestrutura textual (Van Dijk, 1981); e (c) o estudo da coesão textual.

No intuito de levar o aluno a avaliar suas predições, neste segundo tempo da proposta procede-se, primeiramente, a uma comparação das previsões feitas no Pré-Texto com o texto propriamente dito. Observe-se, a seguir, o texto de Carlos José Tavares Gomes e, logo após, a comparação do Pré-Texto com o texto.

\section{ESCURO}

\section{Carlos José Tavares Gomes}

- Mãe, liga a uz. Tem bicho ati. Pedia a menina clementemente, que, por falta de cama no barraco, dormia no chão, perto da cama do casal.

- Fique quieta, minina, me deixa dormi. Berrou o pai.

- Deixa eu ligá a luz pra vê ela, Juão?

- Maria, t'aquieta. Essa minina tá é de manha.

- Mãe, liga a uz. Insistia.

- Já disse pra você calá a boca, sua negrinha. Você vai tomá uma sova se num pará. - Juão, a minina tá chorano. Deixa eu vê ela?

- Não, fique aí. Segurou estupidamente o corpo da mulher que tentara se levantar: - Eu já disse que essa filha da p. tá é de manha tá cum medo do escuro. Escuro é a minha vida. Eu já tenho apurrinhação demais. Medo do escuro. Tô morano de favor na casa do meu ìmão Antônio, tô catano lixo: vendeno pra cumê e essa minina não me deixa descansá um pouco ... vá azucriná o diabo! Gritou colérico.

O silêncio dominou o espaço do barraco: um quarto-cozinh a com um banheiro úmido. Lá fora a noite reinava com seus mistérios. Ela tinha todas as estrelas reluzindo belas acima, no céu da favela. Alguns barracos conservavam a luz acesa. Um batuque anunciava um terreiro de macumba. Ardia no ar um cheiro de maconha. Lá dentro do barraco, só o gemido da criança cortava, fendia, feria o vulto do silêncio. Essa família já não trazia no seio todos os sonhos frescos nem todas as esperanças cor-de-esmeralda, com cheiro ocre de azul. Sua preocupação era a comida - pouca! - do dia-a-dia. Os fantasmas que os homens buscam nesse labirinto há muito desapareceram. Restava agora só o lixo da vida.

- Ai, mãe! Gritou. O choro e o gemido jogaram no quarto-cozinha o terror que invadiu o peito da mãe, Maria. De um salto, deixou a cama e torceu a lâmpada no bocal. A luz varreu o negrume e incendiou a busca no olhar da mãe. Seu olhar buscava em seus pés a filha de três anos, urinada. Notara, antes das poças no chão, manchas de sangue nas cobertas, feridas nas coxas e a fuga de ratos enormes.

\begin{tabular}{|l|l|l|}
\hline & realidade pré-textual & realidade textual \\
\hline local da trama & & \\
\hline personagens & & \\
\hline clima & & \\
\hline levantamento de palavras & & \\
\hline enredo & & \\
\hline
\end{tabular}

A comparação entre as realidades pré-textual e textual propriamente dita tem o objetivo de criar no aluno/leitor o hábito não só de prever, mas também de avaliar suas previsões, estratégias que contribuirão para o aumento de sua aútoconfiança enquanto leitor. Por essa razão, é necessário que o professor mostre a seus alunos que em alguns casos as previsões podem estar erradas. Isto não deve fazer com que o aluno/leitor perca a autoconfiança, mas sim analisar mais conscientemente suas inferências. Portanto, conforme mostra Scott (1983: 70), devemos estar errados em algum momento para assim se fazer necessária uma atitude de flexibilidade.

Em seguida, através de uma seção de exercícios, são abordadas as estruturas profundas (ou superestruturas - Van Dijk, 1981) dos textos estudados. Essa etapa do trabalho objetiva mostrar ao aluno os esquemas mentais que definem a forma do discurso, pernitindo identificar um texto como narrativa, como relato científico ou como descrição, entre outras modalidades. Desta forma, analisam-se os modelos de disposição da tipologia textual, a fim de apresentar aos alunos o "esqueleto" comum a uma determinada familia de textos.

O conhecimento das superestruturas é mais um elemento propiciador do estabelecimento da intertextualidade, pois ao conhecer, por exemplo, o esquema mental que subjaz a produção de uma narração ou de uma argumentação, o leitor irá processar o texto não mais como iniciante, mas sim em função de outros textos já repertoriados em sua memória textual.

Se o texto a ser estudado for de natureza argumentativa, pode-se aplicar, por exemplo, o esquema adotado por Garcia (1975), a respeito dos estágios de uma argumentação informal por contestação: proposição (declaração, tese), concordância parcial, contestação (ou refutação) e conclusão, no intuito de levar o aluno a identificar, entre outras coisas, os procedimentos lingüisticos (estruturas léxicosintáticas) que marcam cada um dos estágios desse tipo de argumentação.

Caso o texto a ser estudado seja narrativo, como o trabalhado neste artigo, pode-se utilizar a estrutura narrativa proposta por Larrivaille (apud Bastos, 1985), composta dos seguintes estágios: estado inicial, denotador (parte do texto em que se apresenta algo que provocará a mudança no estado inicial), ação, sanção (reconhecimento ou não de que a ação se processou) e estado final (onde novamente se instaura um equilíbrio). 


$\frac{\text { NARRAÇÃo }}{\text { (antes) }} \underbrace{\text { ação }}_{\text {denotador }} \underbrace{\text { (depois) }}_{\text {(sanção) }}$

Observe-se, a seguir, a seqüência de exercícios propostos para explorar a superestrutura de Escuro:

1. Relacione as partes do texto Escuro com os itens do esquema abaixo:

(a) estado inicial (parte do texto em que se apresentam os personagens o local onde se encontram, a estória em que se situam etc.);

(b) denotador (parte do texto em que se apresenta algo que provocará uma mudança no estado inicial);

(c) ação (parte do texto em que a transformação provocada pelo denotador se instala):

(d) sançño (constatação ou não de que a ação se realizou); $e$ (inal)).

(e) estado final (parte do texto em que se instala um novo equilibrio

2. Uma narração contém uma série de elementos que correspondem a algumas questões básicas: o quê (fato), quem (personagens), onde (lugar), quando (tempo), como (modo), por guê (causa). Relacione esses elementos com o texto que você leu.

Neste exemplo prático, trabalhei com a estrutura da narrativa proposta por Paul Larrivaille porque, como acentua Bastos (1985: 35), foi utilizada por Mouchon na análise de textos escolares por corresponder melhor ao modelo ternário estereotipado imposto pelas escolas - introdução, desenvolvimento e conclusão. Por outro lado, nada impede que se trabalhe com outros modelos, como o de Van Dijk (1981), o de Fiorin (1989) ou o de Abreu (1990). De qualquer forma, o professor deve estar sempre atento para o fato de que determinadas narrativas nem sempre se estruturam nessa ordem da seqüência canônica; muito pelo contrário: em algumas, as fases da seqüência nem sempre aparecem bem arranjadas, já que poder vir ocultas e, por isso, devem ser recuperadas através das relações de pressuposição (cf. Ilari \& Geraldi, 1990).

Por fim, ainda nesta fase, analisam-se os elementos lingüísticos responsáveis pela tessitura do discurso escrito (coesão). Nesta etapa do trabalho, busco evidenciar os recursos lingüísticos referentes às relações intra e transfrásticas que garantem a instauração da textualidade. Diferentemente de Silva (1992), julgo necessário analisar tanto a coesão referencial (relacionada à remissão de elementos no texto), incluindo, nesse caso, as referências exofórica e anafórica (Bemárdez, 1983), quanto a coesão seqüencial (recursos de superfície responsáveis pela progressão textual), na terminologia de Koch (1989).

Neste sentido, a proposta de Silva (1992) aplica na segunda etapa de seu trabalho (Texto) o estudo dos elementos lingüísticos que têm a função de estabelecer referência, como o são as pró-fonmas (Fávero, 1991), caracterizadas por possuírem baixa densidade sêmica, como os pronomes, os numerais, os advérbios e alguns sintagmas verbais (como 'fez o mesmo', por exemplo). Ao lado desses mecanismos de coesão, julgo oportuno estudar também a coesão seqüencial, uma vez que através desse tipo de coesão se dá a progressão temática, articulando as infornações velhas (conhecidas pelo leitor) às novas (não conhecidas pelo leitor), conforme mostram Beaugrande \& Dressler (1981).

Assim, busco levar o aluno, nesta subparte do trabalho, a perceber que em um texto bem construído é possivel observar a conexão existente entre os vários elementos e compreender que todos estão ligados entre si. Além disso, é conveniente mostrar a eles que 0 uso inadequado dos elementos de coesão confere ao texto passagens obscuras e mal compreendidas e que o domínio dos recursos coesivos é de importância fundamental na compreensão de um texto, pois é por meio de tais mecanismos, responsáveis pelos movimentos prospectivos e retrospectivos que a leitura exige, que se "tece" o texto. A seguir, arrolo alguns exercícios de coesão referentes ao texto trabalhado em aula (Escuro), explicitando as relações de sentido estabelecidas no texto pelos elementos de coesão.

I. Diga ao que se referem, no texto, os termos abaixo:
você (1. 8), ela (. 4), essa negrinha (1.8), seu olhar (1.34), sua preocupação (?. 27),
essa filha da p. (l. 13).
essa filha da $p$. (1. 13).

2. Os textos a seguir apresentam mau uso de conectivos. Procure descobrir a razão desse mau uso e substituir as formas erradas por formas corretas.

(a) A casa da familia era muito humilde, pois titha muita alegria lá.

(b) A menina estava machucada, mas os ratos the feriram.

3. Substitua as palauras grifadas por outras para evitar repetiçôes.

A familia jà não trazia no seio todos os sonhos fiescos. A família não guardava as esperanças cor-de-esmeralda. A preocupaçño da familia era a comida - pouca. A fanı́lia jầ nâo tinha mais esperanças.

4. Observe o seguinte trecho:

Algumas casas conservavam a luz acesa. Os moradores desses lares ainda não haviam se recolhido.

Uma das maneiras de se evitar a repetiçâo palauras idênticas no texto é a substituiçâo por um termo eqüivalente - sinônimo - como no exemplo acima. Faça o mesmo nas frases abaixo:

(a) A criança viu a dona chegar, mas nunca tinha visto aquela - antes;

(b) A mulher nâo gostava do trabalho do marido e pediu que ele mudasse de -

5. Recupere, a partir do texto, os sujeitos dos predicados abaixo:

Insistia (1. 7), Gritou colérico (1. 17); Deixou a cama (. 32). 


\section{Em torno (e além) do texto: o TransTexto}

O terceiro e último momento do trabalho, que denomino de TransTexto, recupe rando o sentido etimológico desse prefixo (em tomo de, além), relaciona-se diretamente com a explicitação de alguns elementos responsáveis pela co erência do texto. Subdivido esta etapa, para efeitos didáticos, em três subpartes:

(a) em um primeiro monento, procuro levar o aluno a explicitar significados implicitos, através de um dos mecanismos responsáveis pela coerência do texto - a intencionalidade (cf. Fávero \& Koch, 1985);

(b) estudo de outros fatores responsáveis pela coerência, tais como a situacionalidade (cf. Fávero \& Koch, 1985);

(c) estudo do que Silva (1992) chama de Pós-Texto.

O primeiro aspecto com que trabalho nesta etapa relaciona-se diretamente à intencionalidade do autor, pois, como se sabe, mostram Koch \& Travaglia (1989:79), o produtor de um texto tem, necessariamente, determinados objetivos ou propósitos, que vão desde a simples intenção de estabelecer o contato com o receptor até a de levá-lo a partilhar de suas opiniōes ou a agir ou comportar-se de determinada maneira.

No intuito de explicitar significados implícitos, procuro levar o aluno a perceber, através de exercicios relacionados ao texto trabalhado, algumas intenç̃es do autor na construção de sentido de seu texto. Desta fonna, viso a exercitar a leitura das entrelinhas textuais, tal como sugere Scott (1983), através de quatro habilidades de raciocínio traçadas por esse autor: (a) fornecimento de informações não dadas; (b) percepção de funções não explícitas; (c) percepção de comentários de ironia, de diálogo autor-leitor e de jdeologia; e (d) explicitação de pressuposições, implicaturas e inferências'. Veja-se, a seguir, como é possivel trabalhar essa interlocução no texto Escuro.

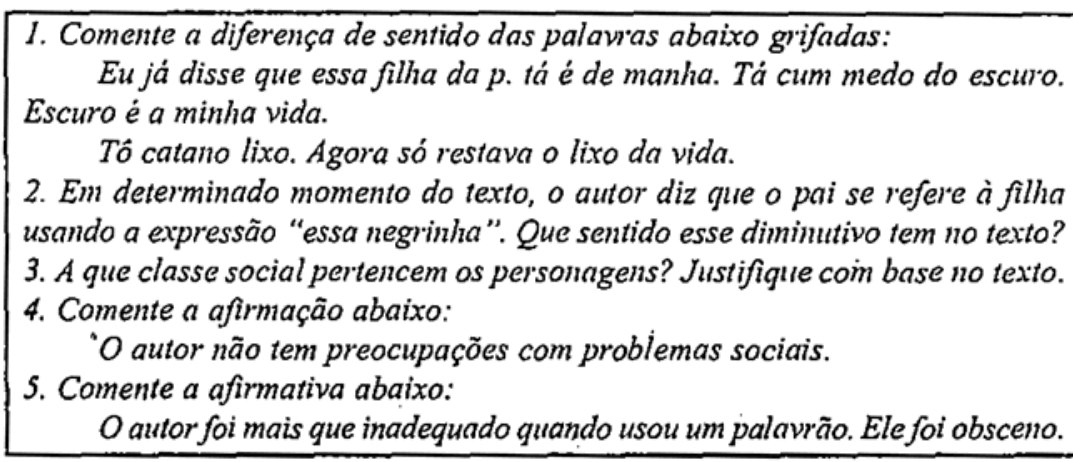

Na verdade, estou utilizando, neste artigo, somente quatro das seis habilidades de raciocinio propostas por Scott (1983).
Através de uma seqüência de exercícios, analisa-se, ainda neste momento do trabalho, a situacionalidade, outro mecanismo responsável pela coerência do texto. A situacionalidade relaciona-se diretamente à adequação em uma dada situação comunicativa: um tex to poderá ser incoerente (ou não-texto) se não for adequado a una situação comunicativa concreta. Conforme mostram Koch \& Travaglia (1989:70), é preciso, ao construir um texto, verificar o que é adequado àquela situação especifica: grau de formalidade, variedade dialetal, tratamento a ser dado ao tema etc. Desta forma, leva-se o aluno a perceber aquilo que é situacionalmente adequado ao contexto de comunicação, através de exercícios que entre outras coisas, versam sobre vocabulário positivo e negativo, formal e informal, e adequação vocabular. Observe-se a seqüência de exercícios a seguir.

1. Você acha que o autor, por não respeitar as regras gramaticais, foi inadequado em sua linguagem? Por quêe?

2. Em algumas situações, palavras que funcionam como sinônimas podem adquirir valores positivos ou negativos como no exemplo abaixo:

Maria pintou os lábios antes de sair: (positivo)

Maria pintou os beiços antes de sair. (negativo)

Substitua a palavra grifada por outra(s) de valor negativo.

(a) A menina foi obrigada a lavar o rosto

(b) Vivia bebendo cerveja no bar;

(c) o aluno tinha a letra horrivel.

3. Indique uma palavra de uso formal correspondente à palavra ou à expressão grifada a seguir.

(a) A noticia deixou João de boca aberta;

(b) O ambiente do bairro é barra pesada.

4. Nas colunas abaixo, escreva sinônimos das palavras anteriores, de modo a apresentá-las como positivas e negativas.

(a) As mulheres dos presos querem novo horário de visita aos (+) $\longrightarrow(-)$.

(b) Muitas prostitutas freqüentam bares de Copacabana. Quando presas, as —_ (+) (+) declaram sempre estar trabalhando.

Por último, objetivo trazer para a sala de aula, tal como propõe Silva em seu artigo de 1989, no Pós-Texto, um pouco da realidade por nós vivenciada que possa de alguma maneira, estar sento tratada no texto estudado. Esta etapa do trabalho proporciona uma chance de trazer para a sala de aula um pouco da vida grande pano-de-fundo de qualquer atividade. Buscamos fazer o aluno pensar refletir, criticar; questionar; alargar sua visão de mundo (Silva, op. cit.: 4). Com isso, espera-se levar o aluno não só a perceber as relações de sentido presentes em um texto, mas também ajudá-lo a colocar-se mais conscientemente no mundo em 
que vive, no intuito de diminuir, ao menos um pouco, o hiato existente entre a escola e a vida. Vejam-se os exercícios para o texto Escuro.

1. Através do texto lido, pudemos perceber que a língua varia nas classes sociais. Você acha que essas diferenças de linguagem sâo positivas ou negativas?

2. Defenda, através de situações do cotidiano, o principio que se segue:

Uin mesmo indivíduo não usa sempre a mesma linguagem. Dependendo da situação, ele será mais ou menos formal ou cerimonioso.

3. Por que os personagens do texto Escuro não dominam os usos cultos da lingua?

4. Como você analisa a situaçâo das pessoas que, como os personagens do texto, vivem à margem da sociedade?

5. Que papel o Estado e a Nação devem exercer para melhorar as condiçôes de vida das pessoas?

\section{Bibliografia}

01. ABREU, A. S. (1990). Curso de redação. São Paulo: Ática.

02. BASTOS, L. K. X. (1985). Coesão e coerência em narrativas escolares. Campinas: EDUNICAMP.

03. BERNARDEZ, E. (1983). Introducción a la linguística del texto. Madrid: Espasa-Calpe.

04. BEAUGRANDE, R. \& DRESSLER, W. (1981). Introduction to textlinguistics. London: Longmann.

OS. FÁVERO, L. L. \& KOCH, I. G. V. (1985). Critérios de textualidade. Veredas 104. Revista da PUC/SP. São Paulo: EDUC, (1): 35-50.

06. FAVERO, L. L. (1991). Coesão e coerência textuais. São Paulo: Ática.

07. —— KOCH, I. G. V. (1984). Lingǘística textual: introdução. São Paulo: Cortêz.

08. FIORIN, J. L. (1989). Elementos de análise do discurso. São Paulo: Contexto.

09. GARCIA, O. M. (1975). Comunicação em prosa moderna. 3a ed., Rio de Janeiro: Fundação Getúlio Vargas.

10. ILARI, R. V. (1986). A lingüística e o ensino da língua portuguesa. São Paulo: Martins Fontes.

11. — \& GERALDI, J. V. (1990). Semântica. São Paulo: Ática.

12. KOCH, I. G. V. (1989). A coesão textual. São Paulo: Contexto.

13. —— TRAVAGLIA, L. C. (1990). Texto e coerência. São Paulo: Cortêz.

14. - A coerência textual. Sâo Paulo: Contexto.
15. MARCUSCHI, L. A. (1983). Lingüística textual: o que é e como se faz. Recife: UFPE/Série Estudos.

16. SILVA, M. da (1989). Alimentando o pensamento crítico. PRAvaLER, Rio de Janeiro, 1 (4): 04

17. - (1992). Como trabalhar o texto no $2^{\circ}$ grau: uma sugestão prática. Rio de Janeiro: UFRJ/Cadernos Didáticos.

18. SCOTT, M. (1983). Lendo nas entrelinhas. Cadernos PUC 16. São Paulo: USP.

19. VAN DIJK, $T$. (1981). Studies in pragmatics of discourse. New York: Mouton Publishers.

20. VIGNER, G. (1989). Intertextualidade, norma e legibilidade. In: GALVES, C. (org.). Texto: leitura e escrita. Sâo Paulo: Pontes.

\section{Summary:}

In this article, I present a suggestion on how to apply the Text Linguistics postulates to Portuguese teaching at elementary and high schools, trying to convert practical exercises into theoretical questions concerning cohesion, superstructure and coherence.

\section{Keywords:}

Text Linguistics, reading, teaching 